\title{
Research on Coal Seam Floor Water Inrush Monitoring Based on Perception of IoT Coupled with GIS
}

\author{
Xiangrui Meng ${ }^{1}$, Junhao Wang ${ }^{1,2}$, Zhaoning Gao ${ }^{1}$ \\ ${ }^{1}$ School of Energy and Safety, Anhui University of Science and Technology, Huainan, China \\ ${ }^{2}$ School of Computer Science and Engineering, Anhui University of Science and Technology, Huainan, China \\ Email: xrmeng1983@163.com
}

Received May 19, 2012; revised June 22, 2012; accepted July 7, 2012

\begin{abstract}
To the complication and uncertainty in coal seam floor water-inrush monitoring, Internet of Things (IoT) perception is applied to the monitoring and controlling of coal seam floor water inrush with major impacting factors analyzed, and an open distribution information processing platform is constructed based on IoT-GIS coupling perception. Then using the platform to comprehensively perceive various floor water inrush impacting parameters, an AHP model is established. At this stage, by means of weight reasoning algorithm based on dynamic Bayesian network, the AHP weight can be worked out using the two-way probability transfer and chain rules. Then the multiple factors are spatially fused by GIS to form a non-linear mathematical model for the calculation of the water inrush relative probability index. After that, the discrimination threshold of the comb graph for the floor water inrush relative probability index is used to further identify the floor water inrush mode. The experiments in $10^{\#}$ Coal Seam of Suntuan Mine show that, the accuracy perceived the floor water inrush is above 92\%, and the platform of IoT-GIS coupling perception has the obvious technical advantage than traditional monitoring technology. Therefore, it has demonstrated strong systematic robustness, important theoretical and application significance.
\end{abstract}

Keywords: Internet of Things; GIS; Coupling Perception; Floor Water Inrush

\section{Introduction}

With the extension of the coal working depth, the coal seam will bear increasingly greater pressures from the karst-containing aquifer. Therefore, the working face is increasingly threatened by the potential floor water inrush, which constitutes one of the greatest hidden dangers threatening safety coal production in mines [1]. The coal seam floor water inrush is resulted from the integrated impacts of the pressurized water, the resistance to the water pressure by the aquiclude and the mine pressure. So, it will be of great significance for us to conduct comprehensive investigations into how to accurately monitor floor water-inrush and bring it under control so that coal mine water disasters will be stopped and safety production guaranteed.

Mine water-inrush can be described by a non-linear process [2] and the inrush can be attributed to the interaction of various factors. However, many a traditional water disaster monitoring methods are insufficient in their failure to conduct a comprehensive analysis of all the impacting factors. Meanwhile, the traditional forecasting method is limited because of great spatial information. So the methods are not desirable when applied to monitoring the actual mine water inrush. Another factor that limits the application is that since mines vary in their hydro-geological conditions, the methods are not sufficiently sensitive in this aspect. Taking all these into account, researchers began to apply GIS and display monitoring process by turning to figures. Literature [3] reports that GIS technology was applied to predict the incident of water inrush in working face and the situation of mine karst water. Literature [4] reports that a coal mine pressurized water prediction model was established by employing the great spatial data processing capacity of GIS and the composite overlay of information spaces used in processing multiple geographic factors.

In the paper, the intelligent Internet of Things and GIS are combined to generate a technology of IoT-GIS coupling perception, which is then applied to monitoring coal seam floor water inrush. And the technology is applied to perceive comprehensively the portent of mine water disasters. Then by comprehensively perceiving the omens for mine water disasters and by turning to corresponding information fusion structure and computation methods, the sensors are working in collaboration and the data obtained are complementary each to the other. With the application, the floor water inrush monitoring and 
predicting capacity is raised and the safety production in coal mines is guaranteed. And to prove our hypothesis, experiments are conducted with desirable results obtained.

\section{Major Coal Seam Floor Water-Inrush Affecting Factors}

Coal seam floor water inrush can be attributed to many factors. In other words, the inrush is resulted from the integral impacts of multiple factors. Therefore, in finding a solution to the problem, we cannot take into account any single contributor. Instead, we should take into account such factors as the original rock stress, the geological structure, the underground water, the impacts exercised by coal working and so on and conduct an integral investigation into the coal seam roof, the coal seam, the coal seam floor and the compressive capacity of the floor. And through on-spot observation and relevant theoretical deduction, we believe that the following are the major factors that exercise impacts on the floor water inrush.

1) The development of karst. In the aquifer composed of limestone, it is easy for karst caves to develop, for karst columns to fall down and for cracks to develop in the karst. In all these cases, space is provided for the karst water. In working, when the working operation reaches the karst breaks and cracks, tunnels will be formed for the karst water to rush into the working face. Therefore, it is a rule that the more developed the karst, the more possible for karst water to rush in and the more quantitative the water inrush.

2) The fault structure. The geological fault is one of the major factors contributing to coal seam floor water inrush. Under the impacts of working, the cracks in the floor will extend and expand so that the pressurized water will go up along the cracks. And when the cracks develop through the floor, water will rush in. Quantitative statistic data show that geological structure contributes to water inrush up to $68 \%, 97 \%$ of the water inrush can be directly attributed to geological faults or to the impacts of geological faults and up to $80 \%$ of the floor water inrush occurs near geological faults [5].

3) Water quantity of aquifer. Water inrush is preconditioned by water resources. No water, no water inrush. And water inrush much depends on water quantity. The quantitative the water, the more frequently the water inrush occurs; and the more dangerous the incident. Experiments demonstrate that the frequency at which the water under the floor rushes into the working face is strongly associated with the aquifer karst development degree and the quantity of the water.

4) Mine pressure. Mine pressure serves as an inducer and trigger for floor water inrush to break out, and the inducing effects are more eminent especially when geological faults exist under the coal seam floor. Together with water pressure, mine pressure helps floor deformation to develop. The development can be attributed to the formation of a damaging belt by working impacts over the aquiclude. Consequently, the strength and water resistance capacity are further reduced and the structural cracks in the aquifer are further extended and expanded. In other cases, before coal working, the pressurized water has approached the coal seam, hence the potential for the water to rush into the working face.

5) Thickness of aquiclude. The aquiclude functions by bringing water inrush under control and the water-proofing capacity of the seam heavily depends on the strength, thickness and geological structure of the seam. In dealing with floor water inrush incidents, it is discovered that in the relevant working face, the aquiclude is generally less than $50 \mathrm{~m}$ thick and in most cases, it is less than $40 \mathrm{~m}$ thick [6]. This shows that the thicker the aquiclude, the stronger the water resistance capacity, and the stronger the mine and water pressure bearing capacity.

6) Water pressure and water temperature. Water pressure is one of the major factors contributing to water inrush and the strength of the pressure determines water inrush occurring frequency. The higher the water pressure, the more frequent the occurrence of water inrush. Variation of water temperature reflects the degree the coal seam floor is damaged and so it is also closely associated with the occurrence of water inrush. Water circulates deeply underground. When it penetrates the aquifer through cracks, the temperature of the rock near the water channel and the temperature of the water in the cracks will become abnormal.

The above analysis shows that coal seam floor water inrush can be attributed to many factors, which function as an integral. Taking all these into account, it is determined that IoT-GIS technology should be applied to monitor dynamically all these major factors that exercise impacts on floor water inrush. In addition, the data obtained by real-time monitoring can be analyzed through information fusion algorithm so that all the possibilities for floor water to rush into working face can be accurately perceived.

\section{The IoT-GIS Perception Platform}

The Internet of Things has introduced a new concept, technology and method into coal mine safety management [7]. For the sake of improving coal mine safety monitoring efficiency, in our studies, the unpredictability of where and when a water inrush will break out and the dynamic working of the mine are fully taken into account with the conclusion drawn that an information perceiving and processing platform should be established for the 
dynamic perception of the coal seam floor safety situation. In other words, only by turning to the distributable, portable and auto-net forming information collection method that is based on the Internet of Things and that is appropriately applicable to coal mine safety can a coal mine perception system be developed to cover all the areas within a mine.

\subsection{The IoT-GIS Perception Principle}

The Internet of Things (or IoT) technology has provided a new concept and method for the safe working in coal mines and serious mine disaster prevention by devising a new system to predict the danger threatening coal mine safety. As an important field in which the perception internet is applied, the coal mine IoT technology combines the sensor technology, distribution computation technology, controlling technology, communications technology and modern mining technology so as to obtain relevant data dynamically and exercise reliable control of the safety production in coal mines [8].

GIS (or Geographic Information System) is a spatial information system for collection, storage, management, analysis and description of spatial data. And it is a discipline that integrates geography, information science, remote sensing and computer technology. It is also a technological system for comprehensively processing and analyzing geographically spatial data. It is an instant spatial analysis technology based on survey, measurement and computer programming. It functions by collecting, storing, displaying, editing, processing, analyzing, outputting and applying spatial data [9].

By combining IoT with GIS to establish a Iot-coupledwith-GIS perception system is meant that the brand new intelligent sensor, the wireless sensing internet and the distribution information processing technology of the Internet of Things are combined with the remote sensing technology of GIS so that the platform can obtain various parameters that affect the coal seam floor water inrush.
Then by comprehensively processing all the variety of information, a complicated nonlinear relationship is established between various impacting factors and water inrush. With IoT coupled with GIS, which can analyze a large quantity of spatial data, the linear characteristics of the spatial information processing by GIS is utilized to perceive the output of the spatial fusion decision making and to obtain the perceived results from monitoring water inrush monitoring. When the intelligent processing method of IoT-GIS is applied to investigations into mine floor water inrush, the great technological advantages for water inrush information analysis, processing and decision making will be brought into full play so that scientific and effective floor water inrush monitoring and controlling can be carried out throughout the mine.

\subsection{The Structure of the Perception Platform by Coupling IoT with GIS}

To exercise dynamic and flexible monitoring of the factors affecting coal seam floor water inrush, it should be taken into account that the working face is a narrow but long geographic space and the zone with relatively the same hydro-geological conditions and under similar working impacts is regarded as the one to be perceived by the Internet of Things. Within the zone, an open distribution IoT-GIS perception network is laid out as shown in Figure 1.

Such physical parameters as stress, strain, water pressure, water temperature and so on collected by the sensor node and data regarding fault structure, karst development, water content and so on obtained by sensor information interpretation will be sent to the sensing center through the IoT. They will be analyzed by the inrush water disaster specialist analysis system and then with the support from GIS, an information fusion algorithm model will be established so that the large quantity of the complicated data can go through the spatial fusion process. And finally, the decision making perception results

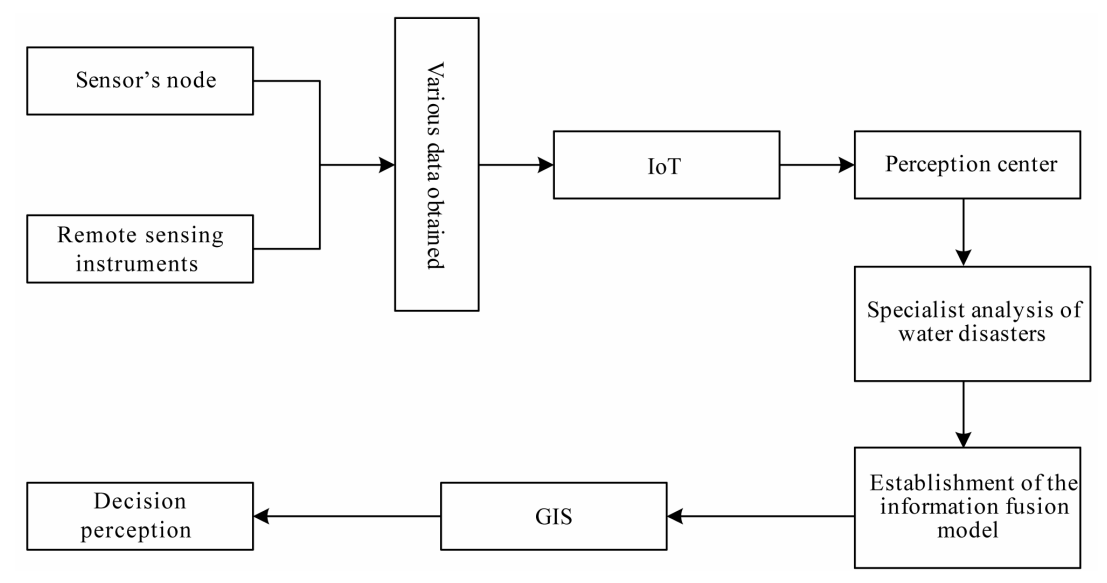

Figure 1. The layout of the distribution IoT-GIS perception platform. 
will be obtained with regard to the coal seam floor water inrush mode. The internet structure is reliable and expansible, able to serve as a distribution perception platform for monitoring coal seam floor water inrush.

\section{Key Steps for Perception Algorithm}

Taking into account the major factors affecting coal seam floor water inrush described in Section 1, the major dominating parameters can be obtained by the distribution perception platform composed by coupling IoT with GIS. When the perceived results are quantified, the AHP model can be established. When the logic advantage of the AHP and the spatial processing power of the GIS are combined, then the AHP weight can be deduced by employing weight deduction algorithm based on the dynamic Bayesian network, the two-way probability transfer and the chain rules. The results will go through the GIS multi-spatial fusion process to form a nonlinear mathematical model. Then by means of the discrimination threshold from the comb graph for the floor water inrush relative probability index, the floor water inrush mode can be identified paving the way for accurate determination of coal seam floor water inrush possibility.

\subsection{The Establishment of the AHP Model}

AHP (Analytic Hierarchy Process) was introduced in middle 1970s by American operational research professor T. L. Saaty, which is quantitative analysis to qualitative problem with a simple, flexible and practical multicriteria decision method. It is characteristic of partitioning complex problems of various factors into interconnected orderly hierarchy, and using mathematical method to calculate the weight value reflecting each level element of the relative importance, which the qualitative and quantitative method are unified to treat various deci- sion factors.

By taking into account the analysis of major factors affecting coal seam floor water inrush, the AHP model is established as shown in Figure 2, where the major factors into which our investigation will be conducted fall into three tiers [10]. Since the present paper primarily aims at conducting an investigation into coal seam floor water inrush, the floor water inrush mode is placed in the first tier. The hydro-geological condition, the geological structure, the aquiclude of the floor and the working situation will determine water inrush possibility but the affecting mode will be determined by relating them to other concrete factors. Therefore, the hydro-geological condition, together with the other three factors, is regarded as an intermediary and is placed in the second tier or the criterion determination tier. The decision making tier or the third tier consists of concrete individual major factors that affect water inrush. When the factors in the third tier have gone through the process of decision making by fusion, the desired purpose can be achieved.

\subsection{The AHP Weight Determination}

Coal seam floor water inrush is resulted from the integrated impacts and different factors will exercise different impacts on it. To gain an accurate knowledge of the extent to which each factor exercises impacts on water inrush, we determine that the AHP weight should be determined by means of the weight reasoning algorithm based on the dynamic Bayesian network, which is established in accordance with the AHP model and is shown in Figure 3 (where the corresponding transfer coefficients in the two tiers are not completely given).

In the above figure, the parent node, $Y=\{y\}$, governs 4 child nodes, $\left\{x_{j}\right\}=\left\{x_{1}, x_{2}, x_{3}, x_{4}\right\}$. The network is tree-structured with a single line connecting the parent

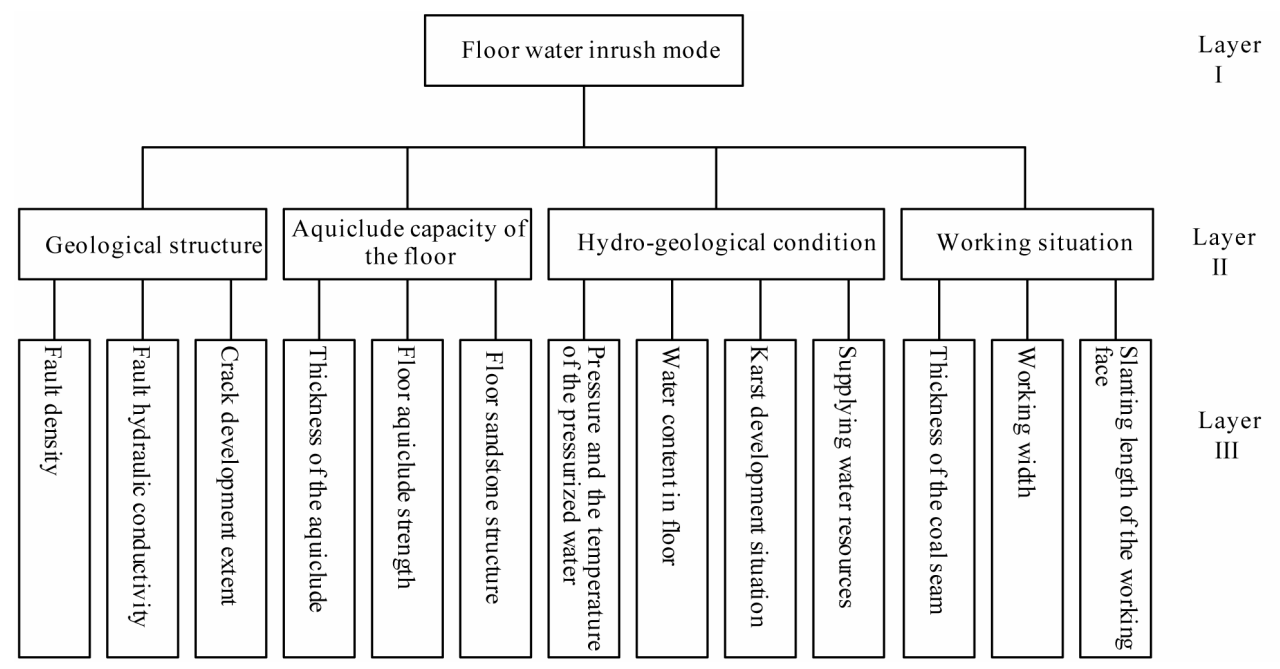

Figure 2. The AHP model for major water inrush controlling factors. 


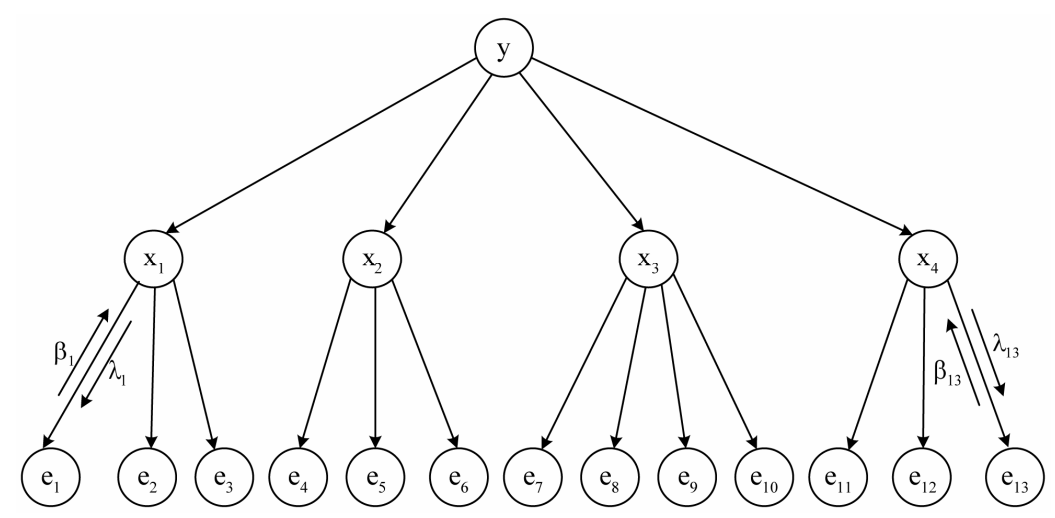

Figure 3. The multi-factored Bayesian network structure.

node to each of the four child nodes. Therefore, each of the four child nodes can be further branched into a set of non-crossing sub-nodes $E$ where

$E=\left\{E_{1}, E_{2}, \cdots, E_{s}\right\}, s=1,2, \cdots, 13$. Let $e=\left\{e_{1}, e_{2}, \cdots, e_{i}\right\}$, or a corresponding assigned value for

$E=\left\{E_{1}, E_{2}, \cdots, E_{s}\right\}$, then based on the Bayesian network, a collaborative probability distribution is determined. When the network satisfies the Markov conditions, by turning to two-way transfer of probability and chain rules [11] and with the upward transfer coefficient corresponding to the decision making tier determined as $\beta_{i}$ and the downward transfer coefficient determined as $\lambda_{i}$, then we will have

$$
\begin{aligned}
& \beta_{i}=p\left(\operatorname{parents}\left(e_{i}\right) \mid e_{i}\right) \sum_{j} p\left(y \mid x_{j}\right) \prod_{i=1}^{s} p\left(e_{i}\right) p\left(y \mid e_{i}\right) \\
& \lambda_{i}=p\left(e_{i} \mid \operatorname{parents}\left(e_{i}\right)\right) \sum_{j} p\left(x_{j} \mid y\right) \prod_{i=1}^{s} p\left(e_{i}\right) p\left(e_{i} \mid y\right)
\end{aligned}
$$

where the parents $\left(e_{i}\right)$ stands for the node of $e_{i}$ in the tier above.

Then by turning to the coefficient for two-way probability transfer between child and parent nodes, the weight for the decision-making tier can be calculated, that is,

$$
w_{i}=\rho \sqrt{\left\|\lambda_{i}-\beta_{i}\right\|^{2}}
$$

where $\rho$ stands for the adjustment factor and $\rho \in(0,1)$. In addition, the constraints can be expressed as $\sum w_{i}=1$.

From what is discussed above, it is clear that the weight reasoning algorithm for the decision-making tier means combining the prior probability distribution with the posterior probability distribution to learn the Bayesian network structure by searching for the node set in the tier above through each node and comparing multiple relevant factors tier by tier in the process of the two-way transfer of data and structure. In this way, the complicated joint probability distribution is decomposed into a series of relatively simple modules. Therefore, the com- plication involved in knowledge acquisition and probabilistic reasoning is greatly reduced [12].

In the formulae, the basic probability value is determined by referring to 1 - 9 scaling methods invented by Professor T. L. Saaty [13]. In addition, in the process of the determination, experts in various fields are consulted. By taking into account the impacts each relevant factor exercises on water inrush and by referring to the experience obtained from their field practice and scientific research and their own knowledge structure and viewpoint, the expert evaluation of the weight of the impacts each relevant factor exercises on water inrush is conducted with a quantified score given to each relevant factor. Then by taking into consideration the accumulated scores, all the relevant factors are compared in terms of the total score for each individual factor. Based on the result, a set of expert evaluation of each of the relevant factor will come into being. Other data are determined by learning the Bayesian network, that is, by parameter optimization learning repeatedly in the structure of a given model. And all the indicator data so deduced do reflect the actual situation.

\subsection{Identification of Water Inrush Model by Means of GIS}

By utilizing the composite function of diverse information of GIS and through the composite processing of the multi-factor space, the information coverage can be composed of the information data for the AHP weights of all the relevant factors so that the information coverage includes all the information about various relevant factors. Then by reading the property table for the coverage, necessary data can be obtained. At this stage, by turning to weighted fusion algorithm, the decision making probability for water inrush can be deduced and it is called the relative probability index for floor water inrush, that is, $I_{r}$.

$$
I_{r}=k \sum w_{i} f_{i}
$$


where $k$ tands for normalization coefficient and $w_{i}, f_{i}$ stand for the weight and quantification value of the $i$-th major impacting factor.

When the floor water inrush is divided into 5 modes, that is, $V=$ threat-free mode, basically-threat-free mode, critical mode, dangerous mode, rushing mode\}, then by turning to probability statistics, the water inrush mode for the corresponding relative probability index can be identified. By using the measured data obtained by mine water inrush monitoring and prevention in the last five years as samples, the water inrush relative probability index for each sample can be figure out by following the abovementioned calculation steps. Revised by classification statistics and fitting, a comb graph can be drawn when the values for water inrush relative probability index, water inrush mode and identification discrimination have gone through simulation analysis. The comb graph is shown in Figure 4 below.

The comb distribution graph shows the discriminated water inrush relative probabilities, whose corresponding thresholds are: $I_{r} \leq 0.1972$ for the threat-free zone;

$0.1972<I_{r} \leq 0.4201$ for the basically-threat-free zone;

$0.4201<I_{r} \leq 0.6595$ for the critical zone;

$0.6595<I_{r} \leq 0.8509$ for the dangerous zone and

$I_{r}>0.8509$ for the rushing zone.

As shown in Figure 5, by turning to comprehensive analysis, the reasoning and decision making process for information fusion-aware algorithm can be obtained. The AHP model is built and the bayesian network is established. And the probability two-way transfer coefficient is derived through bayesian network reasoning based on the corresponding data, so AHP weights is calculated. Then water bursting relative probability index is calculated through the weighted information fusion in GIS information coverage layer, which is used to identify floor water-irruption mode by the division threshold.

\section{Experimental Verification and Analysis}

Suntuan Coal Mine is newly constructed and it is threatened by floor water inrush. The $10^{\#}$ coal seam is the major seam under working. It is rather stable, with the thickness of $1.91-4.11 \mathrm{~m}$ and an average thickness of $3.42 \mathrm{~m}$. The roof and the floor of the seam are mainly composed of mudstone, siltstone and fine-grained sandstone. The $10^{\#}$ coal seam has the 82 coal seam $76.4 \mathrm{~m}$ away above it and the Ordovician limestone 51.69 $68.31 \mathrm{~m}$ (or $58.38 \mathrm{~m}$ on average) away below it. The seam has a recoverable reserve of 139 million tons. However, the coal seam is threatened to some extent by the pressurized water under the floor. The water in the karst cracks of the Ordovician limestone is the major water source that threatens the $10^{\#}$ coal seam, which has witnessed floor water inrush several times and the safe coal production is seriously threatened.

One of the zones in the $10^{\#}$ coal seam was chosen for monitoring major factors exercising impacts on floor water inrush by means of the distribution sensing network platform composed of the Internet of Things coupled with GIS. With the monitoring system stabilized, a

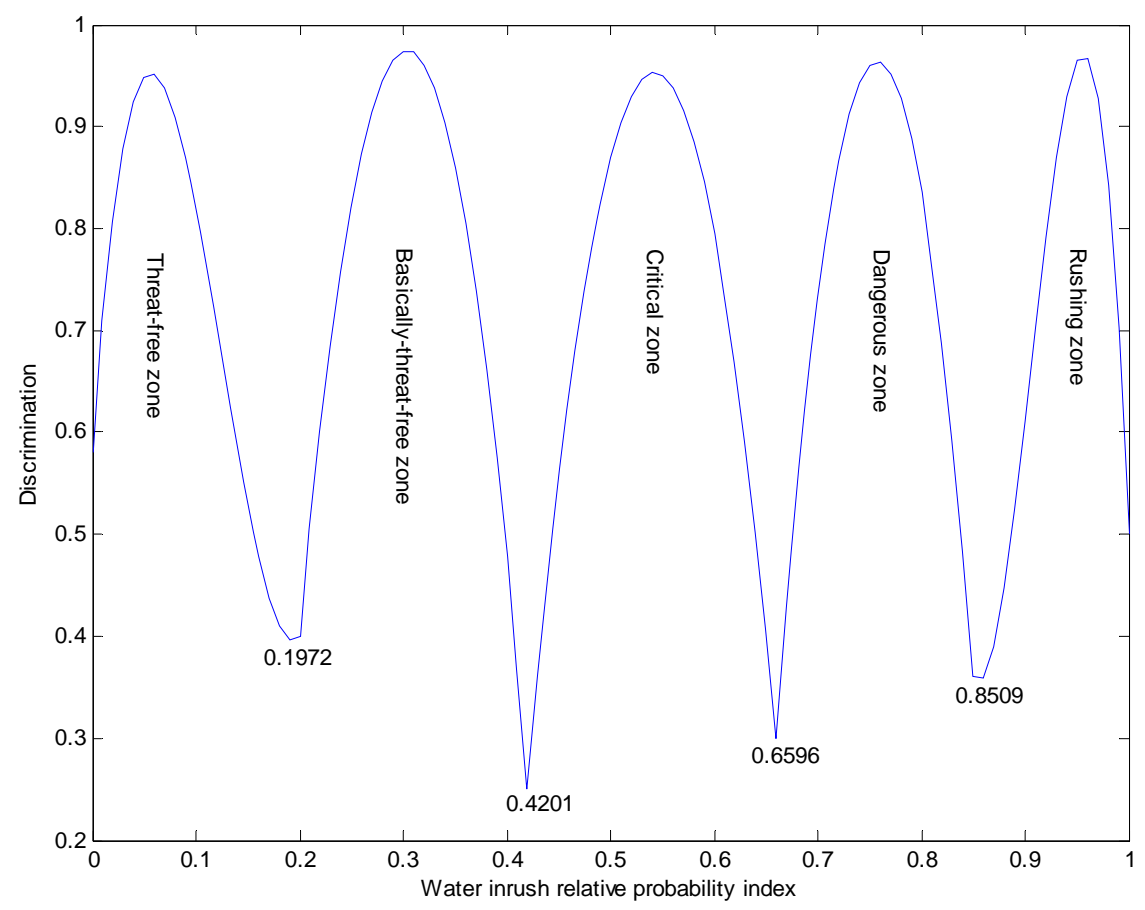

Figure 4. The floor water-irruption relative probability index distribution. 


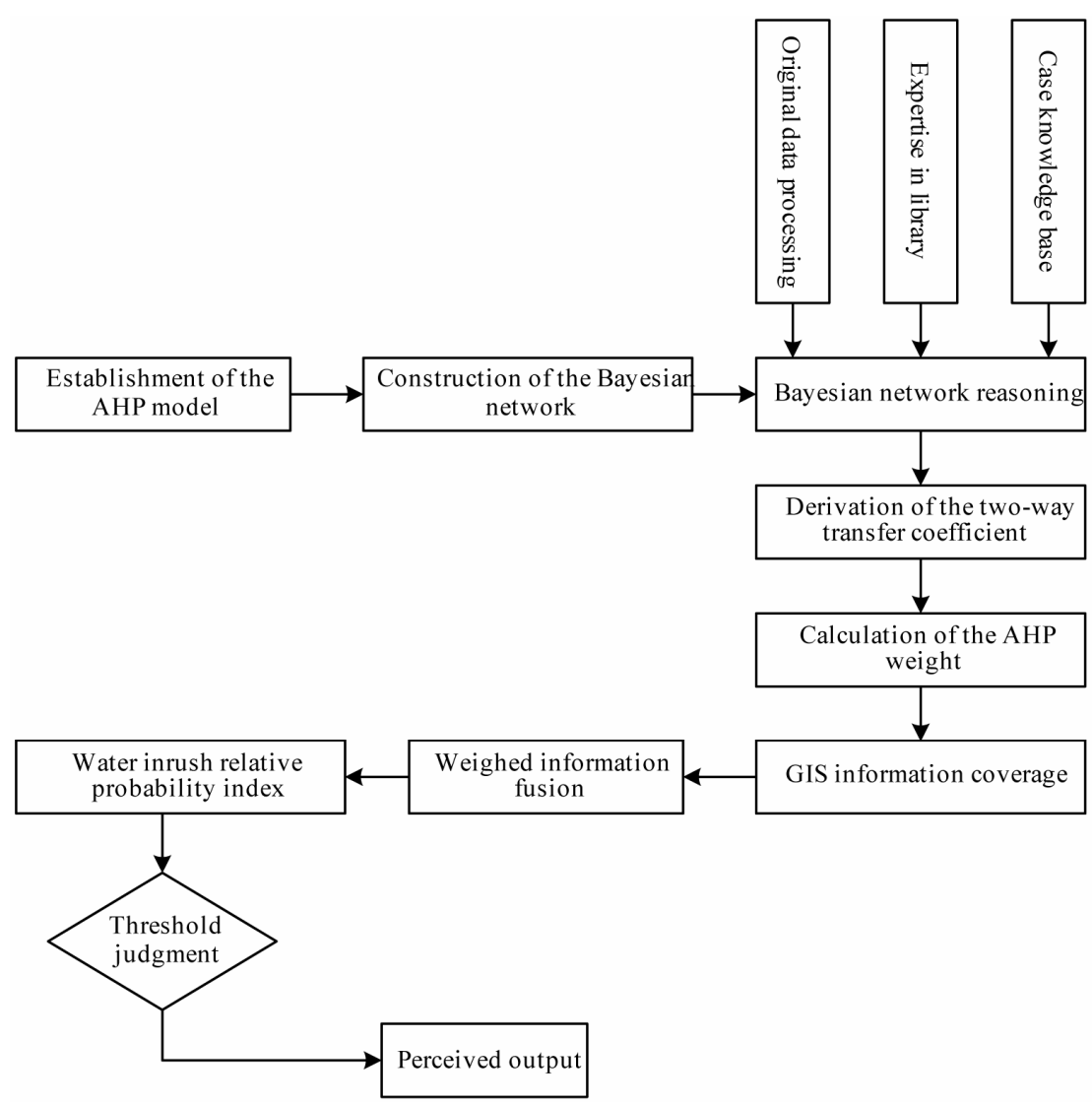

Figure 5. The reasoning and decision making process of information fusion perception algorithm.

set of data were drawn out from the monitoring database. And the drawn set of data served as the set of samples. The weights for various major impacting factors were worked out by weight reasoning algorithm and part of the weights are listed in Table 1 below.

By means of space fusion processing based on GIS and by means of weighted fusion algorithm, from the

Table 1. Part of the weights for main controlling factors.

\begin{tabular}{cc}
\hline Factor & Weight \\
\hline Elevation of the Ordovician limestone roof & 0.1172 \\
Elevation of water in the Ordovician limestone & 0.0432 \\
Thickness of the effective aquiclude & 0.1213 \\
Karst development & 0.1218 \\
Fault density & 0.0354 \\
Compressive strength of the floor & 0.1237 \\
Aquifer water pressure & 0.1389 \\
Water content of the floor & 0.1001 \\
Water temperature & 0.0934 \\
\hline
\end{tabular}

data listed in Table 1, the relative probability index for the floor water inrush was worked out as 0.3426 . From this, conclusion can be drawn that it is a zone basically free of water inrush threat. The survey verification proves that the monitored consequence conforms to the reality.

Then monitoring was conducted throughout the $10^{\#}$ coal seam. After a period of time, as shown in Figure 6, a map was drawn to show all the perceived results concerning floor water inrush smodes. From the different perceived zones, it can be seen that:

1) The threat-free zone is concentrated in the northeast part of the seam. The basically-threat-free zone is mainly located in the area where the Ordovician limestone is not rich in water; the aquiclude is rather thick; and the water pressure in the Ordovician limestone is rather low. The rock strata of the area are mainly composed of mudstone and siltstone, whose internal voids are rather limited in size, and so it is rather poor in hydraulic conductivity. In the east part of the seam, the time-weathered Ordovician limestone crust is rather developed but the fault in the area is not developed and it is so densely filled as not to conduct any water. During the monitoring period, the water temperature, the water pressure and the stress all vary within the safety range. Therefore, it is not possible 
for the area to be threatened by water inrush and in this aspect, safe working is ensured.

2) The basically-threat-free zone is located in the narrow middle part of the seam. The Ordovician limestone in the area is not rich in water and the water pressure is rather low. In addition, the area is geological ideal in that no significant fault is found. However, the area is immediately next to the west part of the seam, where the Ordovician limestone is rich in water supply. In addition, the rock strata are composed of fine to medium-grained sandstone. With the expansion of the internal voids, the possibility for water inrush increases. For this reason, it might be possible for water inrush to break out. And for this sake, appropriate measures should be adopted to prevent it from occurring [14].

3) The dangerous zone is distributed in the west and north part of the seam and water-rushing area is witnessed in No. 2 and No. 3 mining districts. In the area, the coal seam is rather deeply buried, characterized by rather being high in water pressure, rather developed in geological construct and rather rich in water resources (in most parts of the area, though). In the west of the mine, the aquiclude and time-weathered Ordovician limestone crust are rather thin and a few great faults are lying. All these point to the fact that the area is poor in compressive and water-blocking capacity but great in the possibility to be threatened by water inrush. In the areas near No. 2 and No. 3 mining districts in particular, coal working can easily bring damage to the floor, where vertical and horizontal cracks are apparently developed in rock strata and where a strong limestone runoff belt is located. Our monitoring shows that the water temperature, the water pressure and the stress of the area vary greatly, hence the great possibility for water inrush to break out [15].

Generally speaking, the threat-free and basically-threatfree zones are mostly located on the right of the critical zone. The threat-free and basically-threat-free-of zones are more in number than rushing zones and all the identified water-rushing points are within the dangerous and rushing zones. And the perception accuracy is up to more than $92 \%$, indicating that our water inrush perception model conforms to what actually happens.

After that, the traditional water inrush coefficient method and the GA-SVR method [16] are used to process the monitored data so that the water inrush model is identified. Then the false alarm rates and false negative rates are worked out as shown in Table 2 . It can be seen that the method as reported in the present paper can produce desirable perception results and efficiently reduce the false alarm and false negative rates, convincingly,

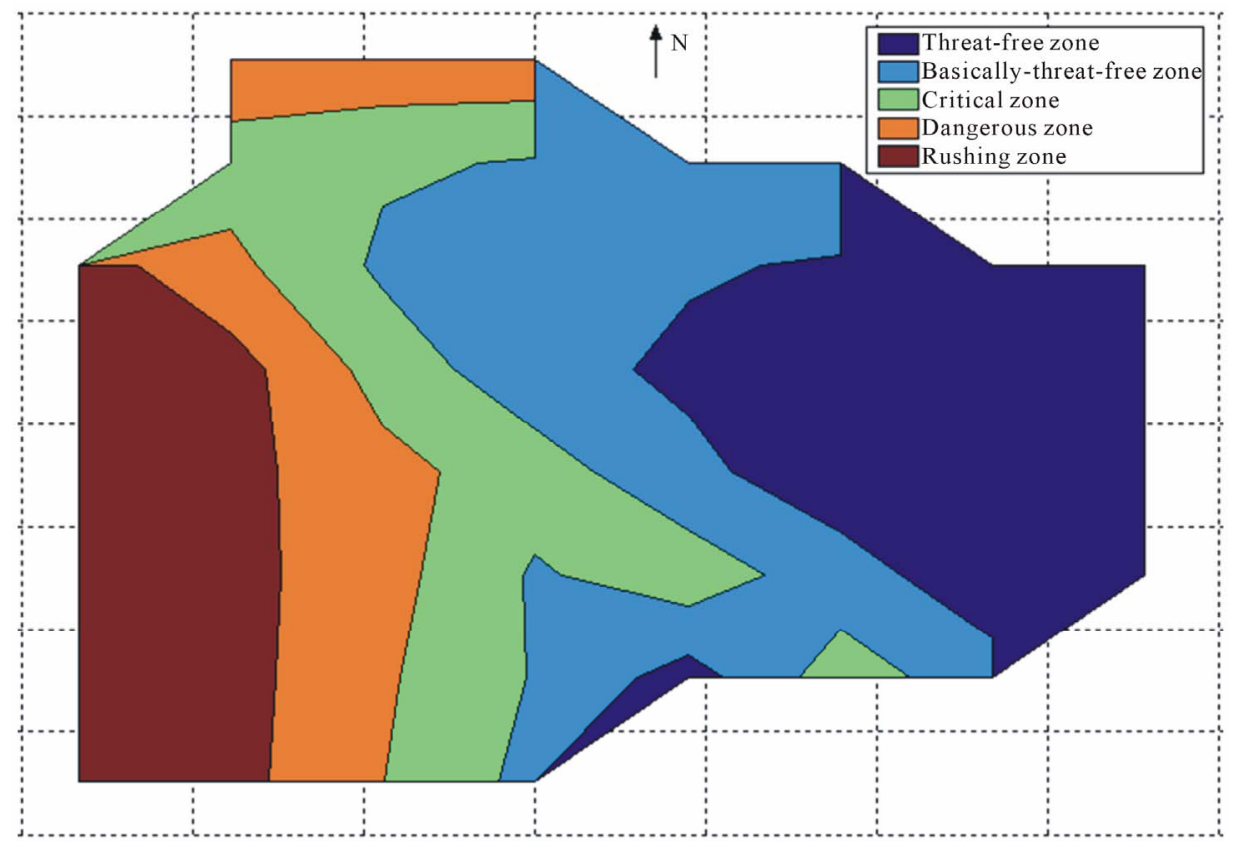

Figure 6. $10^{\#}$ water-inrush perception partition map.

Table 2. The experimental index comparison.

\begin{tabular}{cccc}
\hline Index & Traditional water inrush coefficient method & GA-SVR method & Method reported in the present paper \\
\hline False alarm rate (\%) & 10.21 & 8.06 & 6.74 \\
False negative rate (\%) & 7.35 & 6.10 & 5.03 \\
\hline
\end{tabular}


indicating that the method works well.

Through the above-mentioned experimental analysis it is verified that by means of the perception platform based on IoT coupled with GIS, the monitored results concerned with floor water inrush conform to what really happens. And the water inrush perception algorithm model established in the present paper can accurately tell the basic rules governing water inrush. The perception model does not only utilize the basic geological data but also comprehensively perceive various parameters affecting water inrush. By means of information fusion algorithm, the application of GIS in water inrush analysis model is richly widened. By turning to the nonlinear problem solving reasoning, a nonlinear perception model for coal seam floor water inrush perception can be established [17], in which the interaction of various factors are reflected. The results show that the IoT-coupled-with GIS technology presents a rather systematic robust, and it is of great significance to investigations conducted into monitoring and controlling coal seam floor water inrush.

\section{Conclusions}

1) The Internet of Things has found many applications in coal mines. The present paper focuses on investigations into the application of IoT to monitoring and controlling of floor water inrush by establishing an open distribution information processing platform based on IoT-GIS and using information fusion technology to conduct an in-depth analysis of the data.

2) By means of a comprehensive perception of various parameters affecting floor water inrush, an AHP model is established. And by means of weighted reasoning algorithm based on the Bayesian network, the AHP weight can be derived using two-way probability transfer and chain rules. Then by means of GIS, the multi-factors are space fused to form a mathematical model for working out water inrush relative probability index. Then using the discrimination threshold of the comb graph, floor water inrush can be further identified.

3) By coupling IoT with GIS to form an integral entity, an IoT-GIS platform is established for monitoring floor water inrush. Then by turning to information fusion algorithm, the application of GIS in the floor water inrush analysis mode is greatly widened. Compared with the model by applying GIS for water inrush prediction, the coupled model has reduced human interference and established a nonlinear perception model for the perception of coal seam floor water inrush with various impacting factors clearly reflected. The experiment shows that the IoT-GIS perception technology can be applied to perceive coal seam floor water inrush with the accuracy of more than 92\%. Compared with traditional monitoring technology, the platform is apparently advantageous with a strong systematic robust and so it is of great theoretical and application significance.

\section{Acknowledgements}

The project is sponsored by National Natural Science Foundation (No, 51074003; No. 51074005); it is also sponsored by funds from National Natural Science Foundation Committee and Shenhua Group Corporation Limited (No. 51174255).

\section{REFERENCES}

[1] L. Li and J.-L. Cheng, "Floor Water Irruption Prediction Based on Information Fusion," Journal of China Coal Society, Vol. 31, No. 5, 2006, pp. 623-626.

[2] Y.-L. Li, “A Case Study of Methods and Application of Yaoqiao Mine Water Disaster Based on Multi-Information Fusion Assessmen,” China University of Mining and Technology, Beijing, 2010.

[3] D. S. Zhang, S. S. Zheng, Y. J. Sun, et al., "GIS in Forecasting Coal Mine Flood," China University of Mining and Technology Press, Xuzhou, 1994.

[4] H.-S. Zhang, G.-W. Xue, X.-W. Shi, et al., "Prediction of Water Inrush from Coal Seam Floor by Means of a GeoInformation Composite Overlay Analysis," Journal of China Coal Society, Vol. 34, No. 8, 2006, pp. 1100-1104.

[5] J. A. Wang and H. D. Park, "Coal Mining above a Confined Aquifer,” Rock Mechanics \& Mining Sciences, Vol. 40, No. 4, 2003, pp. 537-551. doi:10.1016/S1365-1609(03)00029-7

[6] W. Liao, R.-Y. Zhou and S.-Q. Li, “A Study of the Nonlinear Forecasting Method for Prediction of Water Inrush from Coal Floor by Means of the Wavelet Neural Network," China Safety Science Journal, Vol. 16, No. 11, 2006, pp. 24-28.

[7] J.-S. Qian, S.-S. Ma and Y.-J. Sun, "Designing of on the Comprehensive Automatic Mining System by Means of the Internet of Things," Coal Science and Technology, Vol. 39, No. 2, 2011, pp. 73-76.

[8] S. Zhang, E.-J. Ding, Z. Xu, et al., "The Second Lecture on Internet of Things and Mine Sensing-Mine Sensing, Digital Mining and Integrated Automatic Mining," Industry and Mine Automation, Vol. 11, 2010, pp. 129-132.

[9] C.-C. Zhang, "The Theories and Methods for Spatial Analysis in GIS,” Wuhan University Press, Wuhan, 2004.

[10] W.-T. Liu, W.-Q. Zhang and J.-X. Li, “An Evaluation of the Safety of Floor Water Irruption Using Analytic Hierarchy Process and Fuzzy Synthesis Methods," Journal of China Coal Society, Vol. 25, No. 3, 2000, pp. 278-282.

[11] I. Tsamardinos, E. Brown and C. F. Aleferis, "The MaxMin Hill-Climbing Bayesian Network Structure Learning Algorithm,” Machine Learning, Vol. 65, No. 1, 2006, pp. 31-78. doi:10.1007/s10994-006-6889-7

[12] N. Friendman and D. Koller, "Being Bayesian about Network Structure: A Bayesian Approach to Structure Discovery in Bayesian Networks,” Machine Learning, Vol. 50, No. 1-2, 2003, pp. 95-125. 


\section{doi:10.1023/A:1020249912095}

[13] T. L. Saaty, “The Analytic Hierarchy Process,” McGrawHill, New York, 1980.

[14] D.-W. Jin, Y.-F. Liu, H. Feng, et al., "Development and Application of Monitoring and Early Warning System for Seam Floor Water Inrush,” Coal Science and Technology, Vol. 39, No. 11, 2011, pp. 14-17.

[15] Z. P. Meng, B. B. Zhang, X. T. Xie, et al., "Evaluation of Water Inrush Risk of Seam Floor Based on IithologyStructure,” Coal Geology \& Exploration, Vol. 39, No. 5,
2011, pp. 35-40.

[16] Q.-K. Cao and F. Zhao, "Forecast of Water Inrush Quantity from Coal Floor Based on Genetic Algorithm-Support Vector Regression,” Journal of China Coal Society, Vol. 36, No. 12, 2011, pp. 2097-2101.

[17] Q. Wu, W. Pang, Y.-C. Dai, et al., "The Technique by Coupling of GIS with ANN as Applied to the Evaluation of the Vulnerability of the Model for Forecasting the Floor Groundwater Bursting,” Journal of China Coal Society, Vol. 31, No. 3, 2006, pp. 314-319. 